\title{
A NOVEL THREE DRUG RIGEMEN (MOXIFLOXACIN -OMEPRAZOLE - NITAZOXANIDE) IN COMPARISON TO TRADITIONAL TRIPLE THERAPY FOR TREATMENT AND ERADICATION OF NAÏVE AND RESISTANT H.PYLORI INFECTION IN DYSPEPTIC PATIENTS
}

By

\section{Mahmoud Mostafa Abd El-Hamid Ahmed Abd El-Aleem Ahmed And Mohammed Zakaria Abu Amer and}

Department of Gastroenterology, Liver and Infectious Disease, Faculty of Medicine, ElAzhar University

Corresponding author: Mahmoud Mostafa Abd El Hamid, Mobile: (+20)01000962976,

E-mail: $\underline{\text { dr7oodasamar@gmail.com }}$

\begin{abstract}
Background: Helicobacter pylori is one of the most common, medically prominent infection worldwide and one of the major causative factor of peptic ulcer disease. So, eradication of H.pylori is effective in healing ulcers, reducing the ulcer recurrence and eliminating the need for maintenance therapy.

Objective: To compare between the efficacy of traditional triple therapy and Moxifloxacin-based triple therapy in treatment of H.pylori infection and to evaluate the efficacy of Moxifloxacin-based regimens as a rescue regimen for H.pylori eradication in resistant patients.

Patients and methods: This study was carried out on 100 Helicobacter pylori (H.pylori) infected patients (within the period between September, 2018 to May 2019) who were enrolled from Gastroenterology, Liver and Infectious Disease Department Al-Azhar University Hospitals (Al-Hussein and BAB Al-Shaarea).

Results: Helicobacter pylori eradication results, in group III as evaluated by monoclonal H.Pylori stool Ag, 6 weeks post therapeutic regimens, reported that eradication rate was $76.9 \%$ (20 patients). Regarding post treatment clinical data in group III; $42.3 \%$ of patients remained having symptoms, and $57.7 \%$ had achieved symptomatic improvement. The best results for H.pylori eradication $90 \%$ was in group II who received Moxifloxacin based triple therapy, compared with group I eradication rate $62.9 \%$ who received traditional triple therapy regimen, and better results $76.9 \%$ in group III (resistant patients from group I).
\end{abstract}

Conclusion: Moxifloxacin can overcome traditional triple therapy resistance.

Keywords: H.Pylori, Moxifloxacin, Omeprazole, Nitazoxanide, Traditional triple therapy.

\section{INTRODUCTION}

Helicobacter pylori (H.pylori) is a small, Gram-negative spirochete inhabiting the mucous layer overlying the gastric epithelial cells in humans. It is the most common prevalent chronic human bacterial infection estimated in 50\% of the global population (Malfertheiner et al., 2012) and the most common cause of 
gastritis worldwide (Chey and Zagari, 2015).

Gastric mucus colonization with H.pylori induces chronic gastric inflammation in all infected individuals, but only induces clinical diseases in 10$20 \%$ of infected individuals. These include peptic ulcers, acute and atrophic gastritis, intestinal meta-plasia, gastric adeno-carcinoma and gastric B-cell lymphoma (Markovska et al., 2011).

Current H.pylori infection preferred treatment involves; proton pump inhibitor (PPI)-based triple or quadruple regimens (McNicholl et al., 2014).

PPI, Amoxicillin \& Clarithromycin is a regimen for global standard care of confirmed H.pylori infection (Chey and Zagari, 2015). Metronidazole (MNZ) is used instead of Amoxicillin or Clarithromycin in cases of allergy or resistance (Malfertheiner et al. 2012).

Current guidelines from the American College of Gastroenter-ology and the European Helicobacter Study Group recommend either a clarithromycin-based triple therapy (a proton pump inhibitor (PPI) plus amoxicillin and clarithromycin) or a bis-muth quadriple therapy (a PPI plus bismuth, metronidazole, and tetracycline) as a standard of care in the treatment of confirmed HP infections. However, a study by Rokkas et al. based on the Maastricht III guidelines, indicated that treatment with a PPI, amoxicillin, and clarithromycin regimen as first-line therapy will fail in $\sim 30 \%$ of patients on an intention-to-treat (ITT) basis, and treatment with PPI, bismuth, metronidazole, and tetracycline as secondline therapy will fail in another $30 \%$, leaving $\sim 10 \%$ of the total patient population in need of an alternative regimen (Chey and Zagari, 2015).

Moxifloxacin,a bactericidal fluoroquinolone antibiotic, has activity against HP due primarily to the drug's activity on bacterial DNA gyrase. Moxifloxacin has been advocated for use in second- and third-line "rescue" regimens. Unfortunately fluoroquinolone resistance, especially in patients who have routinely received a fluoroquinolone for other indications, is of particular concern (Graham and Dore, 2016). A lower dose of moxifloxacin was used to aid in the tolerability of this three-drug regimen, how-ever, as moxifloxacin is a concentration-dependent agent, higher doses may increase eradication rates. Although the optimal dose of moxifloxacin is yet to be determined, our study demonstrated efficacy using the lower dose of $400 \mathrm{mg}$ once daily. Considering the regimen was well tolerated overall, an increase in moxifloxacin dosage may be warranted.

Nitazoxanide is a thiazolide antibiotic indicated for use in adults and children for the treatment of Cryptosporidium and Giardia infections. Unlike metronidazole, nitazoxanide has been shown to be nonmutagenic for HP and to possess antivacuolating toxin activity. In vitro studies indicate nitazoxanide is a potent agent against HP and other anaerobes, having activity against metronidazole-resistant strains (Miyaki et al., 2016). In addition to the in vitro data, others have reported clinical success using nitazoxanide in a two-drug regimen combined with a PPI or sucralfate, and a three-drug regimen with a PPI and amoxicillin (Siddiqui et al., 2016). 


\section{A NOVEL THREE DRUG RIGEMEN (MOXIFLOXACIN -OMEPRAZOLE... ${ }^{1165}$}

Nitazoxanide (NTZ) the first antiparasitic agent reported to be effective against both protozoa and helminthes, particularly in the treatment of intestinal parasitic infestation. NTZ has also shown significant immune- modulation properties, inhibiting lipo-polysaccharide (IPS) -induced pro-inflammatory cytokine production in macrophages (Forde and Reddy, 2010).

NTZ was used as a mono-therapy, as it was a new drug that was unlikely to be affected by the antibiotic resistance of strains in patients who had previous failed therapies (Graham and Fischbach, 2010).

Moreover; Levofloxcicin, PPI, NTZ \& Doxycycline (LOND) regimen with very good results in $90 \%$ cure rate in H.pylori infection was reported by Basu et al. (2011).

The aim of the present work was to compare between the efficacy of traditional triple therapy and Moxifloxacin-based triple therapy in treatment of H.pylori infection and to evaluate the efficacy of Moxifloxacinbased regimens as a rescue regimen for H.pylori eradication in resistant patients.

\section{PATIENTS AND METHODS}

Type of the study: A case control study.

Place: Al Azhar University Hospitals (AlHussein and BAB Al-Shaarea).

Study population: This study was carried out on 100 Helicobacter pylori (H.pylori) infected patients (within the period between September, 2018 to May, 2019) who were enrolled from Hepatology, Gastroenterology\& Tropical Medicine department.
The enrolled patients were divided into 3 groups:

Group I: Seventy naïve patients (not having previously taken or received a particular treatment for H.pylori) with positive H.Pylori Ag were given 14 days of traditional triple therapy (Amoxicillin $1 \mathrm{gm}$ twice daily, Clarithromycin $500 \mathrm{mg}$ twice daily and a PPI $40 \mathrm{mg}$ once daily).

Group II: Thirty patients with positive H.Pylori stool $\mathrm{Ag}$ were given 10 days of Moxifloxacin-based triple therapy composed of Moxifloxacin(400mg once daily) Nitazoxanide $(500 \mathrm{mg}$ twice daily)\& a PPI (40 mg once daily).

Group III: Twenty six patients with positive H.Pylori Ag after treatment (resistant for triple therapy from group 1) were given 10 days of Moxifloxacinbased triple therapy (Moxifloxacin 400 $\mathrm{mg}$ once daily, Nitazoxanide $500 \mathrm{mg}$ twice daily \& PPI $40 \mathrm{mg}$ once daily).

The patients were distributed randomly among the studied groups:

- The study was approved by Ethical committee of faculty of medicine, AlAzhar University.

- Written informed consents were taken from all participants in the study, and also they were informed by any probable side effects that may happen to them.

\section{Inclusion criteria:}

- Patients with dyspeptic symptoms AND have H.Pylori stool Ag +ve.

- Age $>18$ yrs old.

\section{Exclusion Criteria:}

- Active GIT bleeding. 
- Recent use of antibiotics (within 6 weeks).

- Pregnancy and lactating women.

- Previous treatment for HP.

- Allergy to any medication included in the study.

- GIT malignancy.

All the studied subjects were subjected to:

A. Complete history taking and clinical assessment:

- Stressing on symptoms of upper gastro-intestinal tract (GIT) disorders e.g. nausea, vomiting, regurgitation, epigastric pain, heart burn, eructation, fullness, dyspepsia, hematemesis or melena.

- Full general and abdominal examinations.

B Laboratory evaluation:

- Complete blood count (CBC).

- Liver function tests: AST, ALT, S.Albumin.

- Renal function tests: S.Creatinine, S.Urea
C. Stool analysis

D. Stool H.pylori antigen: The test was done at start of study and 6 weeks after completion of treatment therapy for both groups (I\&II). Helicobacter pylori stool antigen (HpSA) using immunecard test (Epitope Diagnostics Inc.,); at the diagnosis \& 6 weeks after the full course of treatment regimens (Gisbert et al., 2006).

The test can be performed on either fresh or frozen stool samples. If the test cannot be performed within one day, the specimen was stored at $-20^{\circ} \mathrm{C}$ or colder.

\section{Statistical analysis:}

Data were collected, coded, revised and entered to the Statistical Package for Social Science (SPSS) version 20. The data were presented as number and percentages for the qualitative data, mean, standard deviations and ranges for the quantitative. Chi-square test was used in the comparison between two groups with qualitative data and Fisher exact test was used instead of the Chi-square test when the expected count in any cell found less than 5. P-value was considered significant when $\mathrm{p}<0.05$.

\section{RESULTS}

There was no statistically significant difference between groups according to age $\&$ sex (Table 1).

Table (1): Comparison between group I \& group II as regards Age \& Sex

\begin{tabular}{|c|c|c|c|c|c|c|}
\hline \multicolumn{2}{|c|}{ Parameters $\quad$ Groups } & \multicolumn{2}{|c|}{$\begin{array}{c}\text { Group (I) } \\
{[N=70]}\end{array}$} & \multicolumn{2}{|c|}{$\begin{array}{l}\text { Group (II) } \\
{[\mathbf{N}=30]}\end{array}$} & p-value \\
\hline \multirow{2}{*}{ Age } & Range & & -62 & & 60 & \multirow{2}{*}{$>0.05$} \\
\hline & Mean \pm SD & & \pm 6.22 & & \pm 6.40 & \\
\hline \multirow{2}{*}{ Gender } & Male & 40 & $57.1 \%$ & 13 & $43.3 \%$ & \multirow{2}{*}{$>0.05$} \\
\hline & Female & 30 & $42.9 \%$ & 17 & $56.7 \%$ & \\
\hline
\end{tabular}




\section{A NOVEL THREE DRUG RIGEMEN (MOXIFLOXACIN -OMEPRAZOLE... ${ }^{1167}$}

There was no statistically significant difference between groups according to injurious agents for patients GIT disorders

(Table 2).

Table (2): Comparison between group I \& group II as regards main GIT injurious agents in the studied groups

\begin{tabular}{|c|c|c|c|c|c|}
\hline $\begin{array}{c}\text { Injurious agents for patients' } \\
\text { GIT disorders }\end{array}$ & \multicolumn{2}{|c|}{$\begin{array}{c}\text { Group (I) } \\
{[\mathbf{N = 7 0 ]}}\end{array}$} & \multicolumn{2}{c|}{$\begin{array}{c}\text { Group (II) } \\
{[\mathbf{N = 3 0 ]}}\end{array}$} & \multirow{2}{*}{ p-value } \\
\cline { 2 - 5 } & $\mathbf{N o}$ & $\mathbf{\%}$ & $\mathbf{N o}$ & $\mathbf{\%}$ & \\
\hline NSAIDs & 8 & $11.4 \%$ & 5 & $16.7 \%$ & \multirow{2}{*}{$>0.05$} \\
\hline Smoking & 11 & $15.7 \%$ & 6 & $20.0 \%$ & \multirow{2}{*}{} \\
\hline outdoor fast food & 25 & $35.7 \%$ & 10 & $33.3 \%$ & \\
\hline caffeine & 15 & $21.4 \%$ & 3 & $10.0 \%$ & \\
\hline more than one factor & 11 & $15.7 \%$ & 6 & $20.0 \%$ & \\
\hline
\end{tabular}

There was a statistically significant before treatment and after treatment in difference between clinical presentation group I, II \& group III (Table 3).

Table (3): Comparison between clinical presentation before $\mathrm{ttt}$ and after $\mathrm{ttt}$ in group I, II \& group III

\begin{tabular}{|c|c|c|c|c|c|c|}
\hline \multirow{2}{*}{ Clinical presentation } & \multicolumn{2}{c|}{$\begin{array}{c}\text { Before } \\
\text { treatment }\end{array}$} & \multicolumn{2}{c|}{$\begin{array}{c}\text { After } \\
\text { treatment }\end{array}$} & \multirow{2}{*}{ P value } \\
\cline { 3 - 7 } Parameters & No & $\%$ & No & \% & \\
\hline $\begin{array}{c}\text { Clinical presentation } \\
\text { (Group I) }\end{array}$ & Asymptomatic & 0 & $0.0 \%$ & 16 & $22.9 \%$ & \multirow{2}{*}{$>0.05$} \\
\cline { 2 - 6 } & Symptomatic & 70 & $100.0 \%$ & 54 & $77.1 \%$ & \\
\hline $\begin{array}{c}\text { Clinical presentation } \\
\text { (Group II) }\end{array}$ & Asymptomatic & 0 & $0.0 \%$ & 18 & $60 \%$ & \multirow{2}{*}{$>0.001$} \\
\cline { 2 - 6 } & Symptomatic & 30 & $100.0 \%$ & 12 & $40 \%$ & \\
\hline $\begin{array}{c}\text { Clinical presentation } \\
\text { (Group III) }\end{array}$ & Asymptomatic & 0 & $0.0 \%$ & 15 & $57.7 \%$ & \multirow{2}{*}{$<0.001$} \\
\cline { 2 - 6 } & Symptomatic & 26 & $100.0 \%$ & 11 & $42.3 \%$ & \\
\hline
\end{tabular}

There was a statistically significant difference between groups according to $\mathrm{H}$ pylori eradication (Table 4).

Table (4): Comparison between group I \& group II as regards post therapeutic eradication results

\begin{tabular}{|c|c|c|c|c|c|c|}
\hline \multirow{2}{*}{\multicolumn{2}{|c|}{ Parameters Groups }} & \multicolumn{2}{|c|}{$\begin{array}{c}\text { Group I (triple } \\
\text { therapy) } \\
\text { N0.=70 }\end{array}$} & \multicolumn{2}{|c|}{$\begin{array}{c}\text { Group II (moxifloxacin- } \\
\text { based therapy) } \\
\text { N0.=30 }\end{array}$} & \multirow[t]{2}{*}{$P$ value } \\
\hline & & No & $\%$ & No & $\%$ & \\
\hline \multirow{2}{*}{ H pylori } & Negative & 44 & $62.9 \%$ & 27 & $90 \%$ & \multirow{2}{*}{0.007} \\
\hline & Positive & 26 & $37.1 \%$ & 3 & $10 \%$ & \\
\hline
\end{tabular}

There was no statistically significant difference between groups according to $\mathrm{H}$ pylori eradication (Table 5). 
Table (5): Comparison between group II \& group III as regards H. pylori eradication

\begin{tabular}{|c|c|c|c|c|c|c|}
\hline \multirow{2}{*}{\multicolumn{2}{|c|}{ parameters Groups }} & \multicolumn{2}{|c|}{ Group II } & \multicolumn{2}{|c|}{ Group III } & \multirow{2}{*}{$P$ value } \\
\hline & & No & $\%$ & No & $\%$ & \\
\hline \multirow{2}{*}{ H pylori } & Negative & 27 & $90.0 \%$ & 20 & $76.9 \%$ & \multirow{2}{*}{$>0.05$} \\
\hline & Positive & 3 & $10.0 \%$ & 6 & $23.1 \%$ & \\
\hline
\end{tabular}

\section{DISCUSSION}

Selection of patients in whom H.pylori induced GIT disease was confirmed by positive (+ve) H.pylori monoclonal stool antigen test.

The recorded high frequency of H.pylori infection in this study, with upper gastrointestinal tract related symptoms and documented gastritis could be due to the fact that Al-Hussein and BAB ELShaarea University Hospitals receive a wide range of population with a relatively poor socioeconomic status and overcrowded conditions.

Regarding sex and age, no statistically significant difference present between the studied groups.

On history taken from the studied groups, the reported suspected injurious agents for their GIT disorders were out door fast food, smoking, non-steroidal anti-inflammatory drugs (NSAIDS), caffeine and more than one factor of mentioned factors with percentages of $35.7 \%, 15.7 \%, 11.4 \%, 21.4 \%, 15.7 \%$ in group I, and $33.3 \%, 20 \%, 16.7 \%$ \& $10 \%, 20 \%$ in group II respectively without statistically significant difference between the studied groups. These reported suspected injurious agents for the studied patients' disorders agreed with Laine et al. (2012), and Begovic \& Selmani (2015).

Helicobacter pylori eradication results as evaluated by H.pylori monoclonal stool antigen, 6 weeks post therapeutic regimens reported that eradication rate was $62.9 \%$ in group I and $90 \%$ in group II with statistically significant difference between the studied groups.

Regarding post treatment clinical data, $22.9 \%$ of patients became asymptomatic, and $77.1 \%$ still symptomatic (heart burn, regurgitation, nusea/vomiting) in group I, with statistically significant difference between pretherapeutic and post therapeutic clinical presentation. In group II, $40 \%$ remained symptomatic and $60 \%$ improved their symptoms with a statistically significant difference between pretherapeutic and post therapeutic clinical presentation. This work studied H.pylori therapeutic regimens based on Moxifloxacin in H.pylori Egyptian patients to explore moxifloxacin efficacy in our community and to evaluate the efficacy of Nitazoxanide as a rescue regimen for $\mathrm{H}$ pylori eradication in resistant patients.

The resistant cases of group I were included in group III and received Moxifloxacin- based triple therapy composed of Moxifloxacin (400 mg once daily), Nitazoxanide (500 mg twice daily) and PPI (Omeprazole 40 once daily).

Helicobacter pylori eradication results in group III as evaluated by monoclonal H.Pylori stool antigen, 6 weeks post therapeutic regimens reported that eradication rate was $76.9 \%$. Regarding 
post treatment clinical data in group III, $42.3 \%$ of patients remained having symptoms and $57.7 \%$ had acheived symptomatic improvement.

Group I who received Clarithromycin, PPI and Amoxicillin regimen achieved the least eradication rate $(62.9 \%)$ with a lot of residual complaints. These results agreed with Yakoob et al. (2010), Kobtan et al. (2012), and Malfertheiner et al (2016).

Group II who received Moxifloxacin, Nitazoxanide, and PPI regimen achieved the best eradication rate $(90 \%)$ with a minimal residual complaints. These agreed with Hwang et al. (2015) who reported that the response to Moxifloxacin based sequential triple therapy versus hyprid therapy as a first line treatment for H.Pylori was 91.3. (Mona et al., 2017) reported that the response to treatment of nitazoxanide was significantly higher than traditional treatment regimen.

\section{CONCLUSION}

Moxifloxacin can overcome traditional triple therapy resistance. in addition to its efficacy in treating naiive patients (who didn't take any medical treatment) with (90\%)and(76.9\%) success rate in resistant patients with shorter therapeutic coarse duration and better patient compliance.

\section{RECOMMENDATIONS}

- Improving the standard of living, socioeconomic status, environmental sanitation \& personal hygiene arc important for elimination \& personal H.pylori infection.

- Multicentre and large scale epidemiological studies of H.pylori infection and the association between its virulence factors and clinical outcome in different regions and populations.
- Public health education programs about H.pylori transmission, complications and resistance

- Early diagnosis and treatment of H.pylori infection minimize its complications.

- H.pylori monoclonal stool antigen test is recommended as a rapid, noninvasive, fast, cheap and easy to perform to detect active infection, monitor therapy effectiveness and H.pylori eradication (6 weeks post treatment).

- H.pylori eradication should be confirmed to accelerate the healing and prevent relapse in PUD as well as GIT malignancies; as H.pylori is classified as a class 1 carcinogen by IARC and WHO.

- Randomized-controlled trials are required to clarify' the H.pylori antimicrobial resistance to our market available regimens.

- Moxifloxacin based triple regimen is recommended H.pylori therapeutic regimen in our community with shorter course duration of treatment and better patient compliance.

\section{REFERENCES}

1. Basu PP, Rayapudi $K$, Pacana $T$ and Mona M. (2011): A randomized study comparing levofloxacin, omcprazole, nitazoxanide, and doxycycline versus triple therapy for the eradication of Hclicobaoter pylori. Am J Gastroenterol., 106: 1970-5.

2. Begovic $G$ and Selmani $R$ (2015): Etiological Factors in Urgent Gastroduodenal Ulcer. Pril (Makedon Akad Nauk Umet Odd Med Nauki), 36(2):203-10.

3. Chey WD and RM Zagari (2015): American College of Gastroenterology guideline on the management of Helicobacter pylori infection. Am J Gastroenterol., 102: 1808-25.

4. Gisbert JP, de la Morena F, Abraira V and Monro M. (2014): Accuracy of monoclonal stool antigen test for the diagnosis of H.pylori 
5. Chan FK, Ching JY, Suen BY and Suzan A. (2011): H.pylori eradication on the longterm incidence of recurrent ulcer bleeding in hi risk aspirin users: a 10-year prospective cohort study (abstr). Gastroenterol; 140; S173-4. Infection: a systematic review and meta-analysis. Am J Gastroenterol., 1011921-30.

6. Forde KA and Reddy KR (2010): Hepatitis $\mathrm{C}$ virus infection and immunomodulatory therapies. Clin Liver Dis., 13(3):391-401.

7. Graham DY and Dore MP (2016): Helicobacter pylori therapy: a paradigm shift. Expert Rev Anti Infect Ther., 14(6):577-85.

8. Graham DY and Fischbach L (2010): Helicobacter pylori infection. N Engl J Med., 363(6):595-6.

9. Kobtan A, Abd Elsalam S, El Kalla F and Fredrec N. (2016): A Nitazoxanide based treatment versus traditional therapy for Helicobacter pylori eradication: a single center experience. Medicine (Baltimore), 95:3879-83.

10. Laine L, Yang H, Chang SC and Robenson Y. (2012): Trends for incidence of hospitalization and death due to GI complications in the United States from 2001 to 2009. Am J Gastroenterol., 107:1190-95.

11. Malfertheiner P, Mégraud F, O'Morain CA, Stevens $J$ and Deric E. (2012): Management of Helicobacter pylori infection-the Maastricht IV/ Florence Consensus Report. Gut, 61(5):646-64.

12. Markovska R, Boyanova L, Yordanov D and Meredeth. M. (2011): Helicobacter pylori oipA genetic diversity and its associations with both disease and cagA, vacA s. m. and i alleles among Bulgarian patients. Diagn Microbiol Infect Dis., 71:33540.

13. McNicholl AG, Marin AC and MolinaInfante J. (2014): Randomised clinical trial comparing sequential and concomitant therapies for Helicobacter pylori eradication in routine clinical practice. Gut., 63(2):244-9.

14. Miyaki A, Yaniaguchi $K$ and Ida $A$. (2016): An assessment of the efficacy of first-line Helicobacter pylori-eradication therapy based on clarithromycin susceptibility. Minerva Gastroenterol Dietol., 62 (3): 234-9.

15. Mona S, Raghda T, Samah $S$ and Meredeth G. (2017): Randomized controlled study of a novel triple nitazoxanide (NTZ) containing therapeutic regimen. Helicobacter, 22:1-5.

16. Siddiqui TR, Ahmed W, Arif A, Monto D and Samar A. (2016): Emerging trends of antimicrobial resistance in Helicobacter pylori isolates obtained from Pakistani patients: The need for consideration of amoxicillin and clarithromycin. J Pak Med Assoc., 66(6):710-6.

17. Yakoob J, Abid $S$, Abbas $Z$ and George MN. (2010): Antibiotic susceptibility patterns of Helicobacter pylori and triple therapy in a high-prevalence area. $\mathrm{Br} \mathrm{J}$ Biomed Sci., 67: 197-201. 


\section{مقارنة بين العلاج الثُلاثى القائم علي (موكسيفلوكساسين-

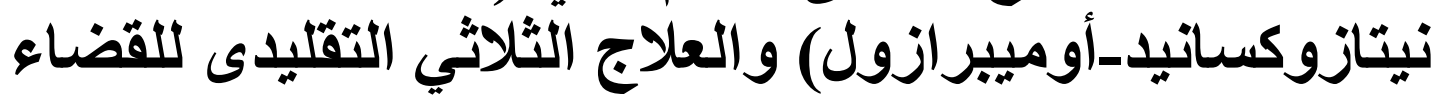

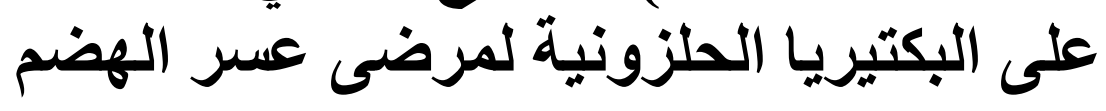

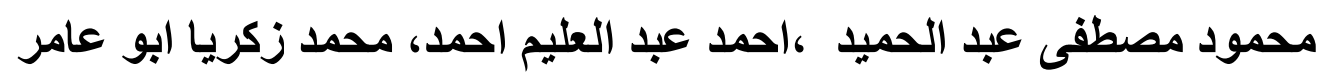
قسم أمراض الكبد والجهاز الهضمي والأمراض المعدية، كلية الطب، جامعة الأزهر، القاهرة، مصر

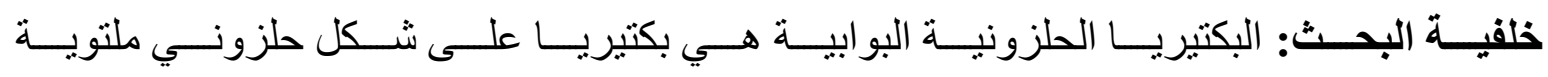

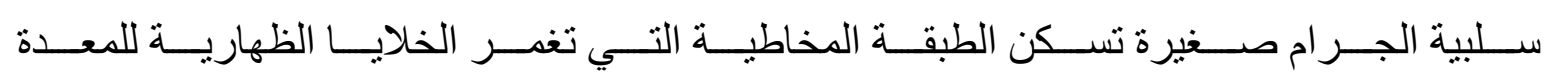

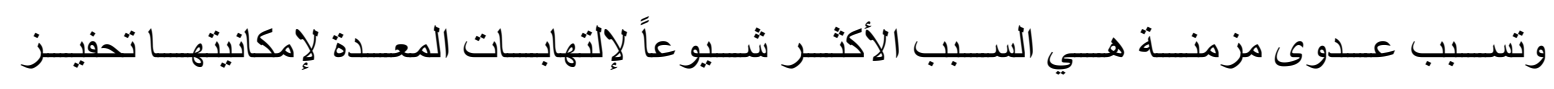

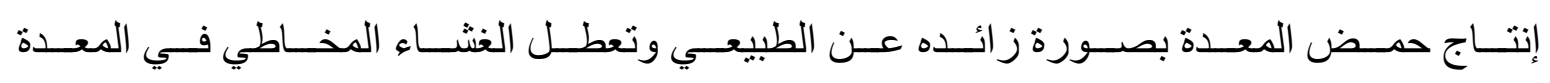

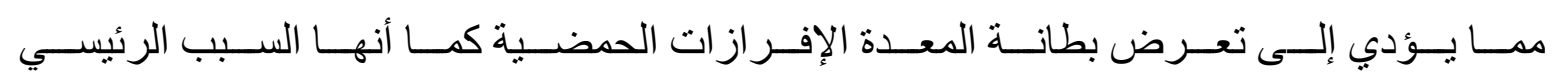

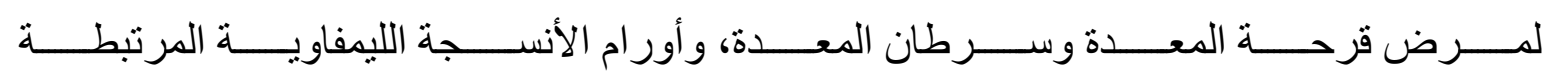
بالأغشية المخاطية.

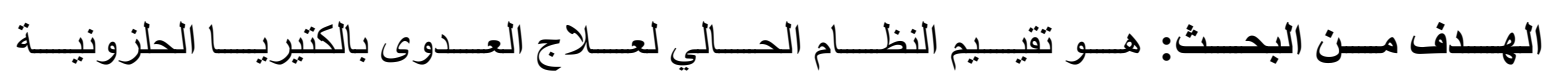

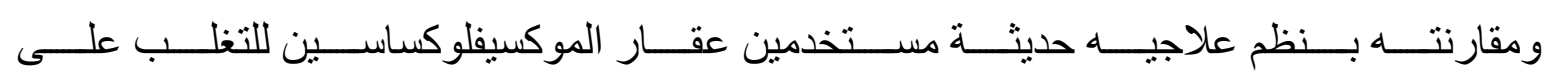

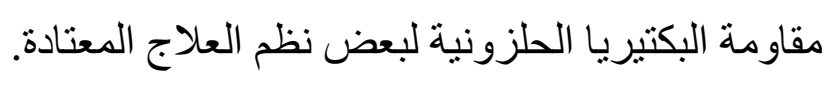

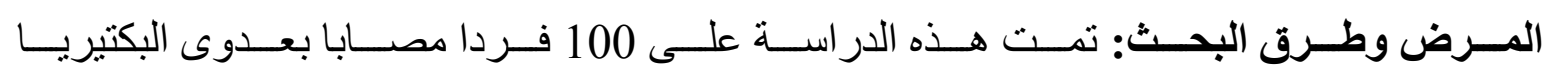

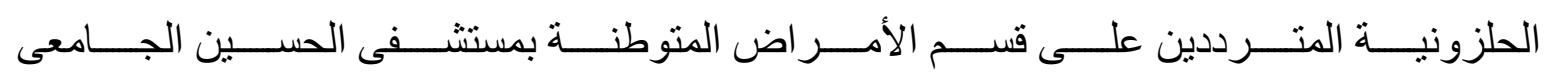

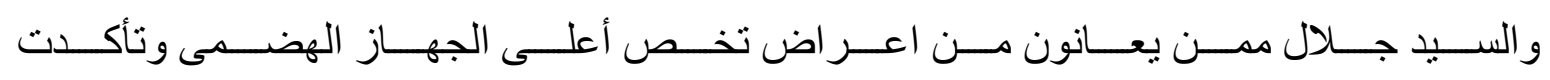

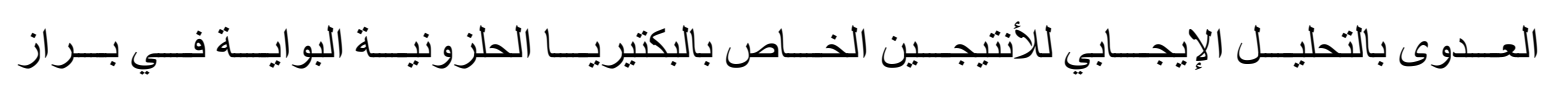

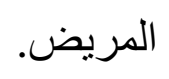

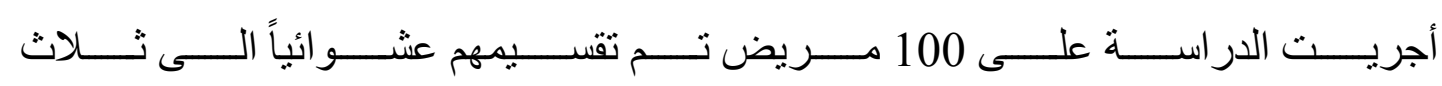
مجمو عات حسب نوع العلاج المستخدم.

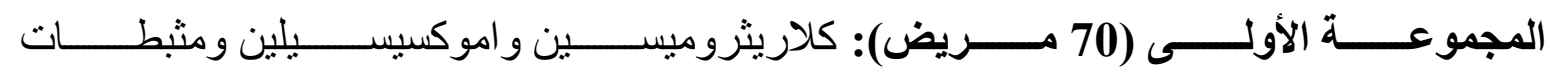
البروتون لمدة 14 يوم. 


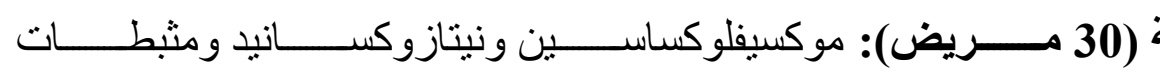

المجموعـــــة الثاتيــــــة البروتون لمدة 10 أيام.

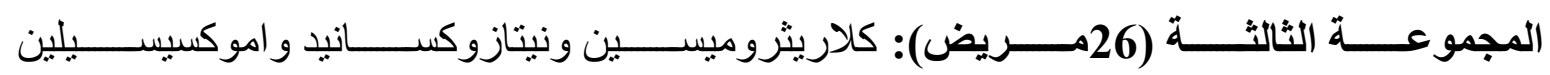
ومثبطات البروتون ولكن للمرضى المقاومين للعلاج من المجموعة الأولى.

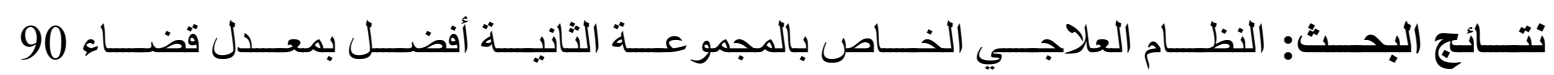

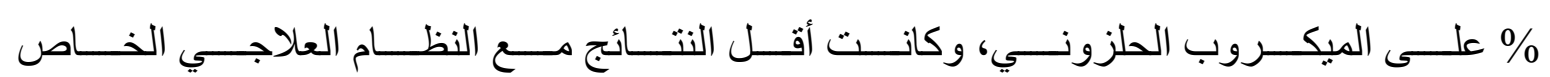

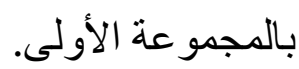

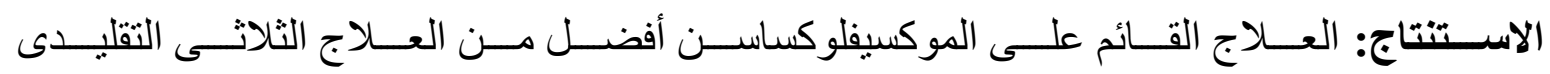
للقضاء على البكنيرسا الحلزونية لمرضى عسر الهضم. 